\title{
CORRESPONDENCE
}

\section{Dose of enteral nutrition and enterocyte biomarker: a circular link?}

\author{
Gaël Piton ${ }^{1,2^{*}} \mathbb{D}$, Amélie Le Gouge ${ }^{3,4}$ and Jean Reignier ${ }^{5,6}$
}

(c) 2019 Springer-Verlag GmbH Germany, part of Springer Nature

\section{Dear Editor,}

Li et al. recently commented [1] our ancillary study [2] of the Nutrirea-2 study [3].

We would like to thank the authors for their analysis.

First, the authors proposed that I-FABP analysis should be correlated with the occurrence of acute mesenteric ischemia. However, acute mesenteric ischemia occurred globally in $1 \%$ of the main study [3], with no case in this sub-study [2].

Second, the authors raised the possibility of a false-positive association between enteral nutrition (EN) and citrulline increase and suggested to perform dose-response analysis. Studying each group separately, we found a trend toward a correlation between the mean caloric intake by EN and the variation of citrulline at day-3 $(r=0.23, p=0.06)$. On the contrary, no correlation was observed in the PN group $(r=-0.1, p=0.42)$. This result could suggest that the higher the dose of EN, the higher the increase of citrulline. However, the link between the dose of EN and plasma citrulline is likely complex and bidirectional. On one hand, trophic EN could be associated with a more beneficial effect than full dose EN, with less enterocyte ischemia and I-FABP release. In this context, we should observe that the lower the EN dose, the higher the citrulline increase. On the other hand, patients having the higher increase of plasma citrulline concentration could be those having a more functional mucosa. In this context, we should observe that the higher the citrulline increase, the higher the dose of EN possibly administered. This complex and circular association needs to be further studied.

\section{Author details \\ ${ }^{1}$ Medical Intensive Care Unit, CHRU Besançon, Besançon, France. ${ }^{2}$ Université de Franche Comté, EA3920, Besançon, France. ${ }^{3}$ Inserm CIC 1415, Tours, France. ${ }^{4} \mathrm{CHU}$, Université de Tours, Tours, France. ${ }^{5} \mathrm{CHU}$ de Nantes, Médecine Intensive Réanimation, Nantes, France. ${ }^{6}$ Université de Nantes, Nantes, France.}

\section{Publisher's Note}

Springer Nature remains neutral with regard to jurisdictional claims in published maps and institutional affiliations.

Accepted: 13 July 2019

Published online: 23 July 2019

References

1. Li W, Li S (2019) Causal inference in secondary analysis of a randomized controlled trial. Intensive Care Med. https://doi.org/10.1007/s00134-01905683-1

2. Piton G, Le Gouge A, Brulé N, Cypriani B, Lacherade J-C, Nseir S et al (2019) Impact of the route of nutrition on gut mucosa in ventilated adults with shock: an ancillary of the Nutrirea-2 trial. Intensive Care Med. https://doi.org/10.1007/s00134-019-05649-3

3. Reignier J, Boisramé-Helms J, Brisard L, Lascarrou J-B, Ait Hssain A, Anguel $\mathrm{N}$ et al (2018) Enteral versus parenteral early nutrition in ventilated adults with shock: a randomised, controlled, multicentre, open-label, parallelgroup study (Nutrirea-2). Lancet 391(10116):133-143 